\title{
Intestinal epithelial cell-specific RAR $\alpha$ depletion results in aberrant epithelial cell homeostasis and underdeveloped immune system
}

\author{
HB Jijon ${ }^{1,2,12,13}$, L Suarez-Lopez ${ }^{3,13}$, OE Diaz ${ }^{4}$, S Das $^{4}$, J De Calisto ${ }^{5}$, M Parada-Kusz ${ }^{1}$, MB Yaffe ${ }^{3,6,7}$, \\ MJ Pittet $^{8}$, JR Mora ${ }^{9}$, Y Belkaid ${ }^{10,11}$, RJ Xavier ${ }^{1,2,9,13}$ and EJ Villablanca ${ }^{1,2,4,9,13}$
}

Retinoic acid (RA), a dietary vitamin A metabolite, is crucial in maintaining intestinal homeostasis. RA acts on intestinal leukocytes to modulate their lineage commitment and function. Although the role of RA has been characterized in immune cells, whether intestinal epithelial cells (IECs) rely on RA signaling to exert their immune-regulatory function has not been examined. Here we demonstrate that lack of RA receptor $\alpha$ (RAR $\alpha$ ) signaling in IECs results in deregulated epithelial lineage specification, leading to increased numbers of goblet cells and Paneth cells. Mechanistically, lack of RAR $\alpha$ resulted in increased KLF4 ${ }^{+}$goblet cell precursors in the distal bowel, whereas RA treatment inhibited klf4 expression and goblet cell differentiation in zebrafish. These changes in secretory cells are associated with increased Reg3g, reduced luminal bacterial detection, and an underdeveloped intestinal immune system, as evidenced by an almost complete absence of lymphoid follicles and gut resident mononuclear phagocytes. This underdeveloped intestinal immune system shows a decreased ability to clear infection with Citrobacter rodentium. Collectively, our findings indicate that epithelial cell-intrinsic RAR $\alpha$ signaling is critical to the global development of the intestinal immune system.

\section{INTRODUCTION}

Vitamin A, through its metabolite retinoic acid (RA), has a key role in embryogenesis, determination of cell lineage, and fate commitment in multiple cell types beyond its well-known role in the maintenance of the retinal epithelium. ${ }^{1}$ In the intestine, vitamin $\mathrm{A}$ has an important role in intestinal immune homeostasis. ${ }^{2,3}$ For example, RA metabolism within dendritic cells was shown necessary and sufficient to induce gut homing molecules on $\mathrm{T}$ lymphocytes, paving the way towards characterization of the role of vitamin A in intestinal immunity. ${ }^{4}$ These studies were followed by reports showing that RA induces gut tropism on B cells, ${ }^{5}$ T-helper subsets, ${ }^{6}$ myeloid precursors, and innate lymphoid cells (ILCs). ${ }^{7,8}$ In addition, RA modulates the generation of Foxp $3^{+}$regulatory $\mathrm{T}$ cells, ${ }^{9-11}$ Th17 cells, ${ }^{9}$ IgA class switching in B cells, ${ }^{5,12}$ intestinal and systemic dendritic cell development, ${ }^{13}$ and the generation and function of group 3 ILCs, in which RA signaling induces the transcription of interleukin-22, one of the functional hallmarks of group 3 ILCs. ${ }^{8,14-16}$ Not surprisingly, vitamin A deficiency results in altered intestinal immune homeostasis and immune responses upon intestinal challenges, ${ }^{17,18}$ which can eventually lead to colorectal cancer progression. ${ }^{19,20}$

${ }^{1}$ Center for Computational and Integrative Biology, Massachusetts General Hospital, Boston, Massachusetts, USA. ${ }^{2}$ Broad Institute, Cambridge, Massachusetts, USA. ${ }^{3}$ David H. Koch Institute for Integrative Cancer Research, Massachusetts Institute of Technology, Cambridge, Massachusetts, USA. ${ }^{4}$ Immunology and Allergy Unit, Department of Medicine, Solna, Karolinska Institute and University Hospital, Stockholm, Sweden. ${ }^{5}$ Faculty of Sciences, Center for Genomics and Bioinformatics, Dental School, Universidad Mayor, Chile. ${ }^{6}$ Department of Biological Engineering, Massachusetts Institute of Technology, Cambridge, Massachusetts, USA. ${ }^{7}$ Division of Acute Care Surgery, Trauma, and Critical Care, Department of Surgery, Beth Israel Deaconess Medical Center, Harvard Medical School, Boston, Massachusetts, USA. ${ }^{8}$ Center for Systems Biology, Massachusetts General Hospital, Boston, Massachusetts, USA. ${ }^{9}$ Gastrointestinal Unit and Center for the Study of Inflammatory Bowel Disease, Massachusetts General Hospital, Boston, Massachusetts, USA. ${ }^{10}$ National Institute of Allergy and Infectious Diseases, National Institutes of Health, Bethesda, Maryland, USA and ${ }^{11}$ Mucosal Immunology Section, Laboratory of Parasitic Diseases, National Institute of Allergy and Infectious Diseases, National Institutes of Health, Bethesda, Maryland, USA. Correspondence: EJ Villablanca (eduardo.villablanca@ki.se)

${ }^{12}$ Present address: Gastrointestinal Research Group, Division of Gastroenterology, University of Calgary, Calgary, Alberta, Canada

${ }^{13}$ These authors contributed equally to this work. 
RA mediates its effects by binding to nuclear receptors: RA receptors (RARs $-\alpha,-\beta$, and $-\gamma$ ) and retinoic X receptors $(-\alpha,-\beta$, and $-\gamma)$. All-trans-RA binds RAR(s), which then dimerize(s) with retinoic $\mathrm{X}$ receptor(s) to activate transcription. ${ }^{1}$ Importantly, unliganded RARs act as transcriptional repressors through the recruitment of cofactors that promote chromatin compaction. Ligand binding leads to a conformational change and recruitment of transcriptional coactivators. Importantly, both transcriptional activation and repression via RARs have been implicated in the regulation of cell fate. ${ }^{21}$

Vitamin A absorption takes place in the small intestine where intestinal epithelial cells (IECs) directly absorb and metabolize pro-retinoid carotenoids into various retinoids. ${ }^{22}$ The intestinal epithelium is a dynamic system with constant turnover. Intestinal stem cells that reside at the bottom of the crypt feed the intestinal gland with proliferative progenitors that, after several rounds of division, stop proliferating and terminally differentiate into two distinct linages: absorptive and secretory. Absorptive cells or enterocytes are responsible for the absorption of nutrients and they represent the more abundant cell type in the small intestine. The secretory lineage gives rise to goblet cells (mucus secretors), enteroendocrine (hormone producers), and Paneth cells (producers of antimicrobial agents and lysozyme). ${ }^{23}$ Both goblet cells and enteroendocrine cells populate the villi, whereas Paneth cells stay at the bottom of the crypt having critical roles in maintaining homeostasis between the host immune system and the microbiota. ${ }^{24,25}$ Although much is known regarding pro-retinoid metabolism within IECs, little is known about retinoid signaling in these cells and whether this signaling contributes to the maintenance of intestinal immune homeostasis.

In the present study, we specifically targeted the RAR $\alpha$ isoform in murine IECs to determine whether epithelial intrinsic RAR $\alpha$ signaling participates in the establishment of intestinal mucosal homeostasis. Deletion of RAR $\alpha$ within the IEC compartment revealed altered differentiation and function of the epithelial barrier, resulting in a dramatic increase in the numbers of goblet cells and Paneth cells, as well as a decrease in the number of enteroendocrine cells. This observation was paralleled by changes in microbiota composition and microbial-epithelial interactions. Furthermore, we found decreased ILCs and isolated lymphoid follicles in the colon. Interestingly, mice with deletion of $\operatorname{RAR} \alpha$ in the IEC compartment showed reduced clearance of the attaching and effacing bacteria $C$. rodentium. Collectively, these studies indicate that RAR $\alpha$ signaling in IECs controls epithelial cell differentiation and function, which broadly impacts the composition and function of the intestinal mucosal immune system.

a

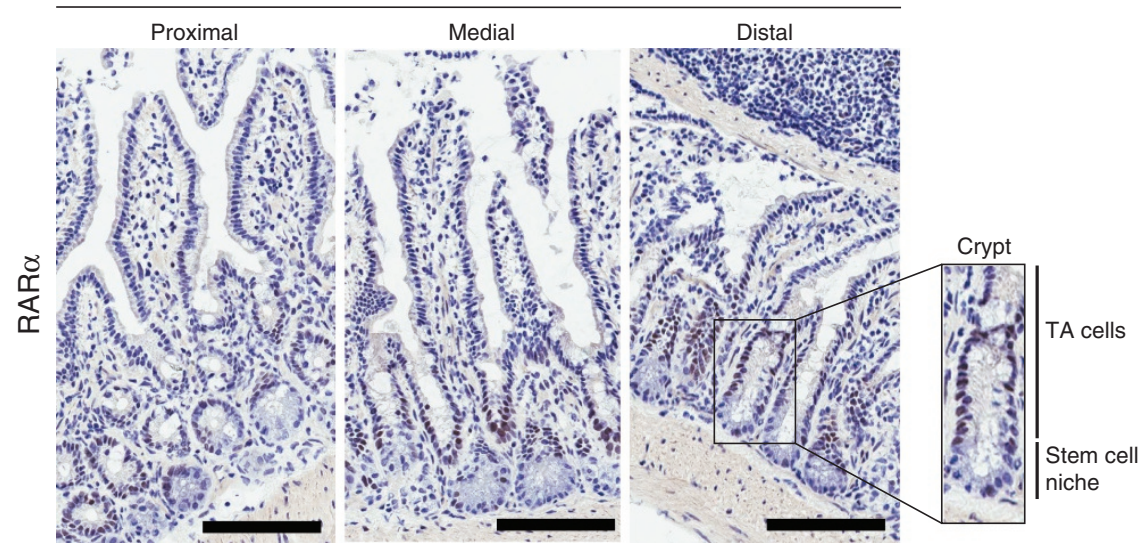

b

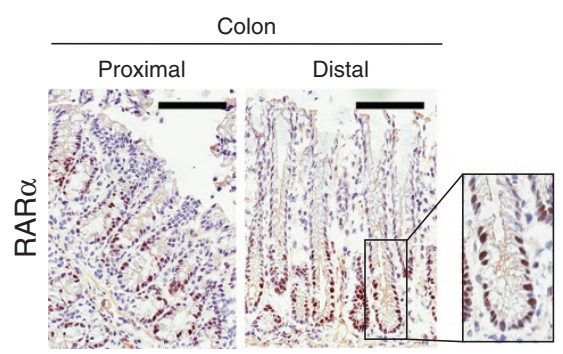

C

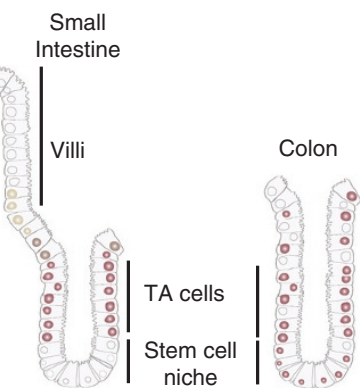

d

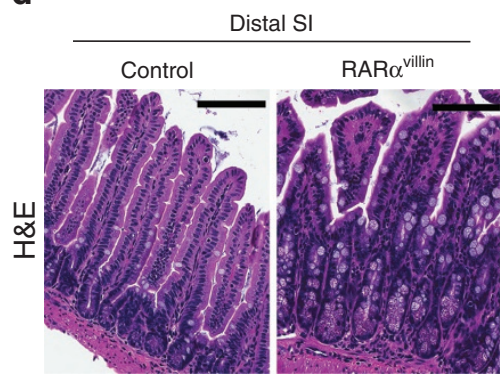

Figure 1 Retinoic acid receptor- $\alpha(R A R \alpha)$ expression in intestinal epithelial cells (IECs) from the small intestine and colon. Frozen sections from the proximal, medial and distal small intestine (a) and proximal and distal colon (b) were stainied for RAR $\alpha$. Onsets show a digital magnification of the crypt within the respective boxes. (c) Cartoon showing the RAR $\alpha$ expression pattern through the crypt-villi axis (small intestine) or crypt (colon). One representative figure out of three experiments. (d) Hematoxylin and eosin (H\&E) staining of distal small intestine sections of control and RAR $\alpha^{\text {villin }}$ mice. One representative figure out of three experiments. TA, transit amplifying. Scale bars, $100 \mu \mathrm{m}$. 


\section{RESULTS}

\section{Deletion of RAR $\alpha$ within IECs results in dysregulated} epithelial lineage commitment

Although RA signals through different RAR isoforms, deletion of RAR $\alpha$ has been shown sufficient to impair RA signaling within the immune system. ${ }^{19,20,26}$ Hence, we analyzed the pattern of RAR $\alpha$ expression within the intestinal mucosa. We observed that $\mathrm{RAR} \alpha$ expression in the small intestine follows a gradient in the intestinal gland, being absent at the bottom of the crypt (stem cell niche), expressed in the early progenitors of the transit amplifying zone and then decreasing as cells migrate to the top of the villi. In contrast, colonic crypts express RAR $\alpha$ both in cells within the stem cell niche and the transit amplifying compartment (Figure 1a-c). To investigate the role of RAR $\alpha$ signaling in IECs in vivo, we examined the effects of conditional deletion of RAR $\alpha$ within the IEC compartment on intestinal immune composition and function. Mice with conditional targeting of the $R A R \alpha$ locus $\left(\mathrm{RAR} \alpha^{f / f}\right)$ were crossed with cre-expressing mice to enable the specific deletion of $R A R \alpha$ in IECs $\left(\mathrm{RAR} \alpha^{f / f} \times\right.$ Villin-cre). Examination of Cre recombinase expression in the small intestine confirmed villindriven expression starting in the upper crypts towards the top of the villi, whereas the bottom of the crypts and lamina propria remained negative (Supplementary Figure S1a online). This is in agreement with Cre expression in Villin-cre mice described by Gumucio et $a .^{27}$ The resulting $\mathrm{RAR} \alpha^{\text {villin }}$ mice showed partial depletion of RAR $\alpha$ in progenitor cells (transit amplifying cells), which varies along the intestinal tract (Supplementary Figure S1b). RAR $\alpha^{\text {villin }}$ mice were born in normal Mendelian ratios and were grossly normal. We found no differences in body weight or in longevity as monitored for 2 years (data not shown). Examination of intestinal hematoxylin and eosin staining suggested differences in epithelial cellular composition (Figure 1d). We therefore next examined whether $R A R \alpha$ deficiency resulted in altered patterns of epithelial differentiation. We found that $R A R \alpha$ deficiency in IECs resulted in increased numbers of goblet cells and Paneth cells within the most distal segments of the small intestine in RAR $\alpha^{\text {villin }}$ mice compared with their control counterparts (Figure 2a-d). By contrast, we observed decreased numbers of enteroendocrine cells in RAR $\alpha^{\text {villin }}$ mice compared with controls (Figure 2e and $\mathbf{f}$ ). Aberrant proportions on secretory cell lineages suggest an altered homeostasis in the intestinal crypt after RAR $\alpha$ depletion.

In order to gain further mechanistic insights, we analyzed both proliferative capacity and apoptosis in IECs lacking RAR $\alpha$. We observed significant differences exclusively in the proximal small intestine, whereas the colon as well as medial and distal small intestinal segments showed similar numbers of cleavedcaspase $3^{+}$apoptotic cells in RAR $\alpha^{\text {villin }}$ compared with control animals (Supplementary Figure S2a), suggesting that apoptosis is unlikely to account for the increase in secretory IECs observed in RAR $\alpha^{\text {villin }}$ mice. By contrast, the number of Ki- $67^{+}$proliferating cells was significantly enlarged in $\mathrm{RAR} \alpha^{\text {villin }}$ mice showing the most pronounced differences between control and $\mathrm{RAR} \alpha^{\text {villin }}$ mice within the distal rather than proximal small intestine (Supplementary Figure S2b, c). Similarly, differences were most prominent in the distal colon (Supplementary Figure S2d, e). Changes in the proliferative compartment and cell differentiation did not result in altered crypt length throughout the small intestine of RAR $\alpha^{\text {villin }}$ mice (Supplementary Figure S2f). Altogether, these data suggest that $\mathrm{RAR} \alpha$ signaling in the transit amplifying compartment controls proliferation and secretory cell lineage commitment in late progenitors.

\section{RA-RAR $\alpha$ axis modulate the expression of the goblet cell master regulator KLF4}

We next assessed the possibility that RAR $\alpha$ controlled proliferation in differentiated secretory cells. To this end, mice were injected with bromodeoxyuridine (BrdU), which is incorporated in proliferating cells and we co-stained for BrdU together with Lyzozyme (Paneth cells) and Muc2 (Goblet cells). We were not able to detect colocalization between proliferating $\mathrm{BrdU}^{+}$cells and either Paneth or goblet cells (Figure 3a). We next assessed whether secretory cell hyperplasia was associated with altered stem cell homeostasis in the absence of RAR $\alpha$. Positive cells for olfactomedin-4, a robust intestinal stem cells marker, ${ }^{28,29}$ was comparable between RAR $\alpha^{\text {villin }}$ and control animals (Supplementary Figure S3a, b), suggesting that increased secretory cell numbers were not associated with expansion of the stem cell pool at the bottom of the crypt. Although we cannot completely exclude that RA might modulate stem cell functions, our data suggest that RA-RAR signaling does not modulate stem cell homeostasis, which is in agreement with $\mathrm{RAR} \alpha$ expression in transit amplifying cells (Figure 1a).

The transcription factor Krüppel-like factor 4 (KLF4) has been shown to be a master regulator of terminal goblet cell differentiation. ${ }^{30,31}$ We then addressed if KLF4-expressing cells (goblet cell precursors) were altered in RAR $\alpha^{\text {villin }}$ mice. Staining of KLF4 in the small and large bowel showed significantly increased $\mathrm{KLF}^{+}{ }^{+}$cells in the distal small intestine and colon (Figure $3 \mathbf{b}, \mathbf{c}$ ). To investigate whether RA is sufficient to regulate klf4 expression, we took advantage of the zebrafish system, in which RAR signaling and the mechanisms controlling goblet cell differentiation appear to be highly conserved when compared with mammals. ${ }^{32}$ As expected, $72 \mathrm{~h}$ post fertilization embryos exposed to $1 \mu \mathrm{M}$ RA for $36 \mathrm{~h}$ showed increased levels of the RAR target gene cyp26a1 (Figure 3d). Treatment with RA resulted in decreased klf4 transcript levels compared with untreated embryos (Figure 3d), which was associated with decreased goblet cell numbers as seen by Alcian blue staining (Figure 3e), suggesting that the RA-RAR $\alpha$ axis negatively modulates $k l f 4$ expression, which might impact goblet cell differentiation.

\section{Conditional $\operatorname{RAR} \alpha$ deletion in IECs results in $R e g 3 \gamma$ overexpression and microbial dysbiosis.}

Paneth cells and goblet cells are responsible for the production and secretion of a variety of antimicrobial peptides (AMPs), such as Reg3 $\gamma$ to maintain a gap between the microbiota and the epithelial layer. ${ }^{33,34}$ Our results showing increased numbers of 
a

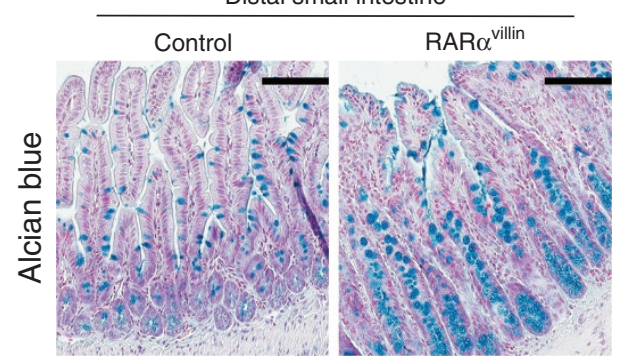

C

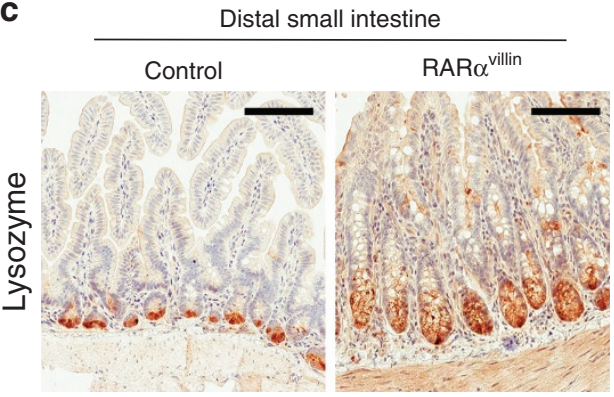

e

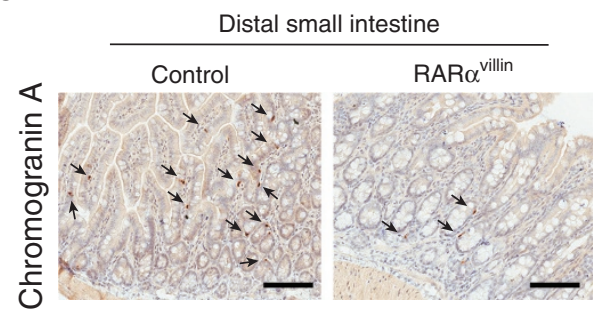

b

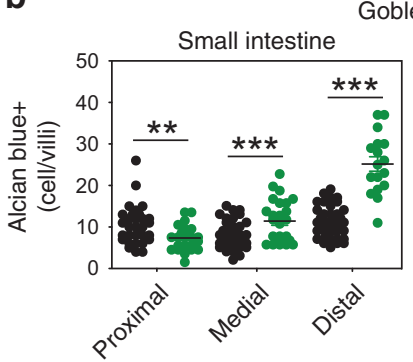

Goblet cells

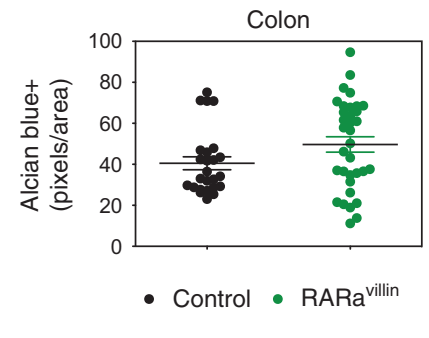

d

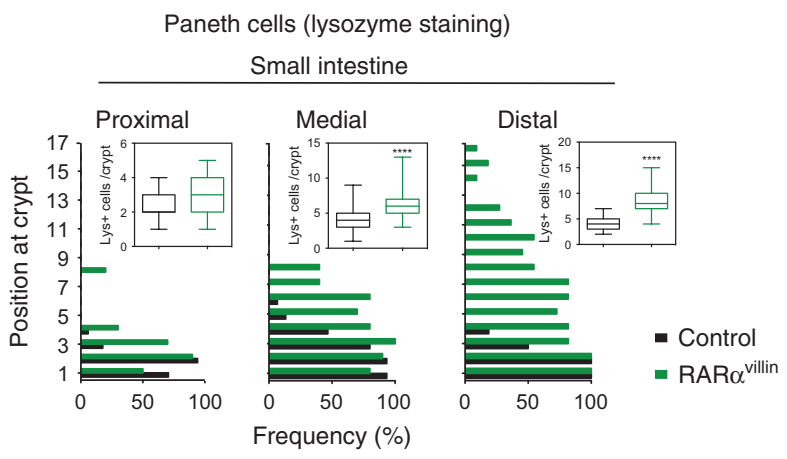

f

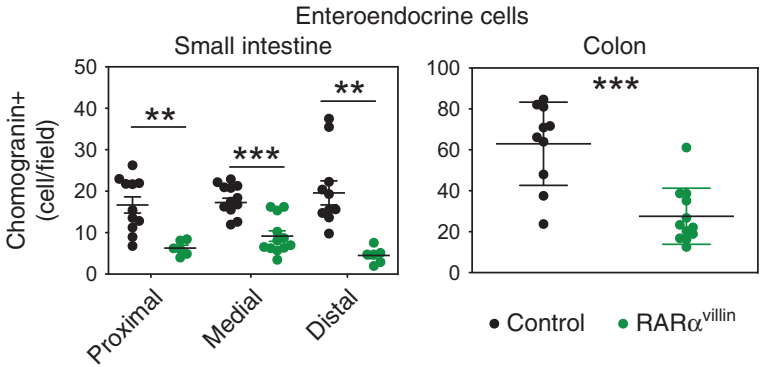

Figure 2 Retinoic acid receptor- $\alpha(\operatorname{RAR} \alpha)$ controls epithelial homeostasis. (a, b) Mucin-containing goblet cells were stained with Alcian Blue and their number per villus determined. (c, d) Paneth cells were immunostained with anti-lysozyme and their number per villus and position along the crypt-villus axis determined ( $n=7-19$ villus/mouse). (e, f) Enteroendocrine cells were immunostained with anti-Chromogranin $\mathrm{A}$ and their number per villus determined ( $n=7-12$ villus/mouse). Data in $\mathbf{a}$ and $\mathbf{b}$ are representative of three mice/genotype. ${ }^{\star \star} P<0.01$ and ${ }^{\star \star \star} P<0.005$; Student's $t$-test. Error bars represent s.e.m. in all panels. Scale bars, $100 \mu \mathrm{m}$.

Paneth cells and goblet cells, particularly in the distal small intestine, suggested possible differences in the AMP levels and composition of the microbiota. We therefore analyzed a panel of AMPs produced by Paneth cells. Although we did not detect changes in Defa-rs1, we observed significantly higher Ang4 transcript levels in the proximal small intestine, whereas Reg3g transcript levels were higher in both proximal and distal small intestine, from RAR $\alpha^{\text {villin }}$ mice compared with controls (Figure 4a). As Reg3 $\gamma$ deficiency results in increased bacterial colonization at the ileal epithelial cell surface, ${ }^{34}$ we investigated the presence of luminal commensal bacteria close to the epithelium using fluorescence in situ hybridization. In agreement with higher Reg3 $\gamma$ levels, we observed decreased luminal commensal bacteria in the ileum of RAR $\alpha^{\text {villin }}$ mice compared with control counterparts (Figure $4 \mathbf{b}$ and $\mathbf{c}$ ). Analysis in the colon showed similar bacterial loads between RAR $\alpha^{\text {villin }}$ and control mice. Next, we analyzed the relative abundance of different bacterial genera in the small intestine and colon of $\mathrm{RAR} \alpha^{\text {villin }}$ and control mice using quantitative PCR. Interestingly, whereas Clostridia, Enterobacteriaceae, Bacteroides, and Lactobacillus did not differ in the small intestine luminal content between $\mathrm{RAR}^{\text {villin }}$ mice and control mice, we found significant differences in lactobacillus in the colon and in segmented filamentous bacteria in both the ileum and colon of RAR $\alpha^{\text {villin }}$ mice compared with control mice (Figure 4d). Altogether, these data suggest that RAR $\alpha$ deficiency in the intestinal epithelium results in increased Reg $3 \gamma$ levels, which might alter bacterial colonization at the ileal epithelial surface.

\section{RAR $\alpha$ in IECs is required for proper intestinal immune homeostasis}

IECs and the microbiota provide inputs that help shape the composition and function of the intestinal immune system. ${ }^{35,36}$ 


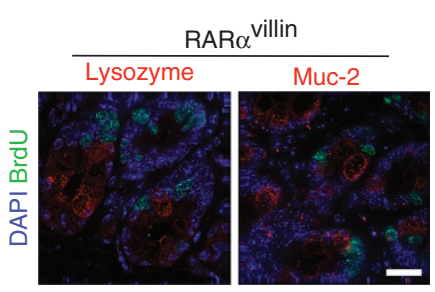

b

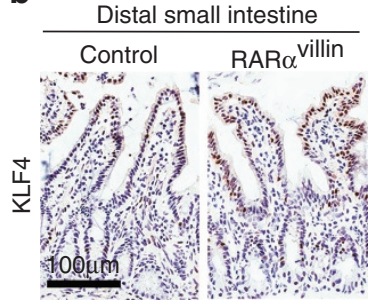

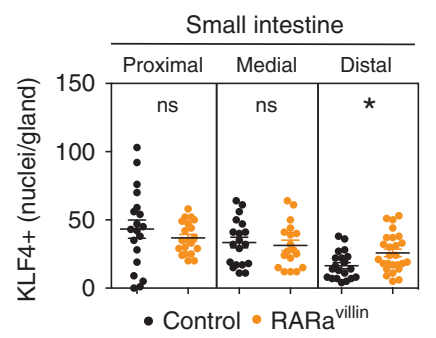

C

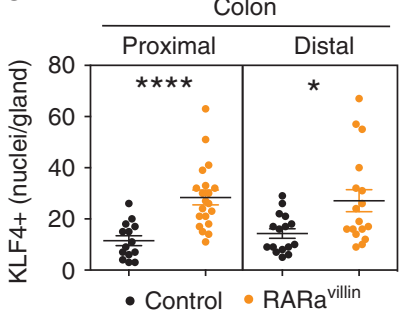

d

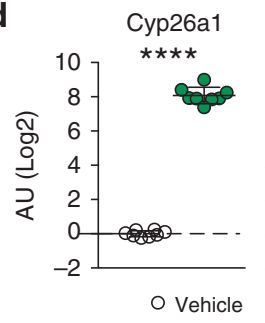

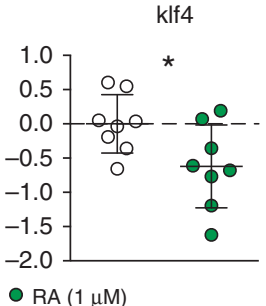

e
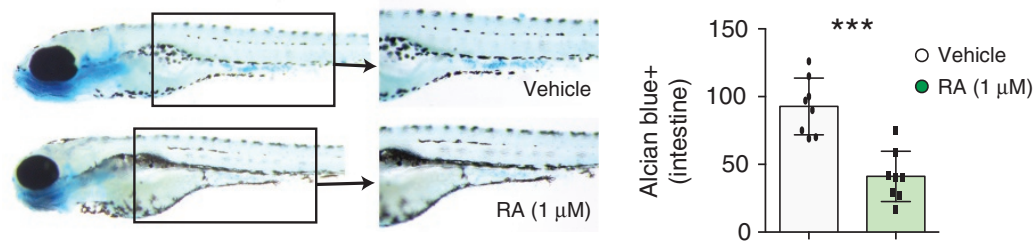

Figure 3 Retinoic acid receptor- $\alpha($ RAR $\alpha)$ modulates differentiation within the secretory branch through Krüppel-like factor 4 (KLF4). (a) Proliferative cells were identified by bromodeoxyuridine (BrdU) incorporation in parallel with lysozyme or Muc-2 to detect paneth cells (left) and goblet cells (right), respectively. (b, c) KLF4 expression was measured in the distal small intestine (b) and colon (c) by immunohistochemistry and number of positive nuclei were counted per intestinal gland. Seven to 10 crypts were counted per intestine section in 2 mice per genotype. (d) Reverse-transcriptase quantitative PCR analysis of RAR target gene cyp26a1 and the transcription factor klf4 in zebrafish embryos treated with either vehicle or $1 \mu \mathrm{m} \mathrm{retinoic} \mathrm{acid} \mathrm{(RA)} \mathrm{from}$ $72 \mathrm{~h}$ post fertilization (hpf) till $108 \mathrm{hpf}$. Each dot represents a pool of 20 embryos. The mRNA expression was normalized to that of ef $1 \alpha$. (e) Whole-mount alcian blue staining of zebrafish embryos treated with either vehicle or $1 \mu \mathrm{m}$ RA from $72 \mathrm{hpf}$ till $108 \mathrm{hpf}$ (images). The graph represent quantification of Alcian Blue-positive cells per intestine ( $n=8$ per group). ${ }^{\star} P<0.05$, ${ }^{\star \star *} P<0.005$, and ${ }^{\star \star \star \star} P<0.001$, Student's $t$-test. Error bars represent s.e.m. Scale bar, $20 \mu \mathrm{m}(\mathbf{a}), 100 \mu \mathrm{m}(\mathbf{b})$.

As our data showed that mice lacking RAR $\alpha$ in IECs displayed alterations within IECs and the microbiota, we next assessed whether loss of RAR $\alpha$ in IECs impacts the intestinal immune compartment by examining whether the immune composition of the lamina propria in RAR $\alpha^{\text {villin }}$ mice was altered. We first performed an unsupervised analysis of flow cytometry data using t-distributed stochastic neighbor embedding. ${ }^{37} \mathrm{CD} 45^{+}$ $\mathrm{DAPI}^{\text {neg }}$ lamina propria cells were exported, concatenated, and displayed in a single t-distributed stochastic neighbor embedding contour plot in which clusters defining macrophages and DC subpopulations were determined based on specific markers (Supplementary Figure S2). Comparison between samples, in which number of events were kept constant, showed an overall relative decrease in DC subpopulations in the RAR $\alpha^{\text {villin }}$ compared with control mice (Figure 5a). Similarly, two-dimensional dot plots revealed that the mononuclear phagocytic compartment, defined as $\mathrm{CD} 11 \mathrm{c}^{\mathrm{hi}} \mathrm{MHC}$ $\mathrm{II}^{\text {hi }}$, was decreased by almost one-third in RAR $\alpha^{\text {villin }}$ mice compared with control mice (Figure $5 \mathbf{b}$ and $\mathbf{c}$ ). Within mononuclear phagocytic cells, dendritic cells (defined as $\mathrm{CD}_{103}{ }^{+}$) and macrophages (defined as $\mathrm{CD} 64^{+} \mathrm{CD} 103^{-}$) were decreased 3 -fold and 0.5 -fold in RAR $\alpha^{\text {villin }}$ mice compared with control mice, respectively (Figure $\mathbf{5 b}$ and $\mathbf{c}$ ). As analysis by flow cytometry requires enzymatic digestion to generate cell suspensions, and therefore can result in genotypedependent damage to sensitive cell types, we confirmed our findings through immunohistochemistry. Immunohistochemical staining in small intestinal "Swiss rolls" confirmed decreased numbers of $\mathrm{CD}_{11 \mathrm{c}}{ }^{+}$cells in
$\mathrm{RAR} \alpha^{\text {villin }}$

mice

com-

pared with control mice (Figure 5d), further supporting the observations obtained by flow cytometry.

Intestinal $\mathrm{CD}_{103}{ }^{+}$dendritic cells possess the ability to metabolize vitamin A into $\mathrm{RA},{ }^{38}$ and are thus capable of efficiently inducing Foxp $3^{+}$T regulatory cells, gut tropism on $\mathrm{T}$ and B cells, and interleukin-22 production by group 3 ILCs. ${ }^{39}$ The ability to metabolize RA requires the activity of retinaldehyde dehydrogenases, which can be monitored using the ALDEFLUOR (ALDE) assay. ${ }^{40}$ Whereas almost $14 \%$ of $\mathrm{CD}_{11 \mathrm{c}^{+}} \mathrm{MHC}^{-\mathrm{II}^{+}}$cells were $\mathrm{CD} 103^{\mathrm{hi}} \mathrm{ALDE}^{+}$in the small intestine of control mice, we found a significantly lower proportion (only $\sim 3 \%$ ) of $\mathrm{CD} 103^{\text {hi }} \mathrm{ALDE}^{+}$dendritic cells in $\mathrm{RAR} \alpha^{\text {villin }}$ mice (Figure 5e). In addition, mean fluorescence intensity analysis revealed significantly lower ALDE activity per $\mathrm{CD}_{103}{ }^{+}$dendritic cell in cells from RAR $\alpha^{\text {villin }}$ mice compared with their control counterparts (Figure 5e). Collectively, these results suggest that RA signaling in IECs is crucial for the development of intestinal dendritic cells that have the ability to produce RA.

\section{RAR $\alpha^{\text {villin }}$ mice have reduced numbers of isolated lymphoid follicles}

As reduction in intestinal dendritic cell numbers as well as defects in RA production by $\mathrm{CD} 103^{\text {hi }}$ dendritic cells could result in decreased numbers of $\mathrm{T}$ cells in the intestine, ${ }^{41}$ we next compared the presence of lymphocytes in the small intestine. Immunohistochemistry staining with $\mathrm{CD} 3$ revealed that $\mathrm{T}$ cells are present throughout the small intestine lamina 
a

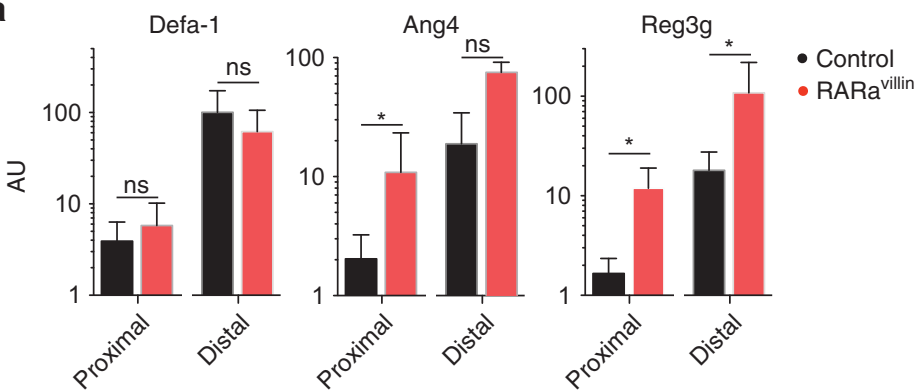

b
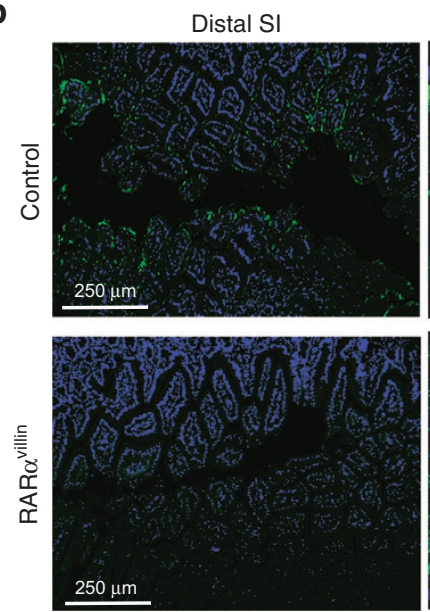

16S rDNA (universal probe) DAPI
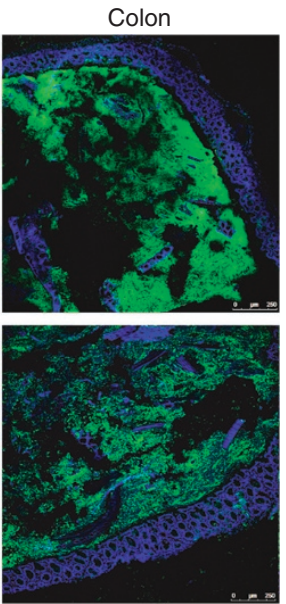

C

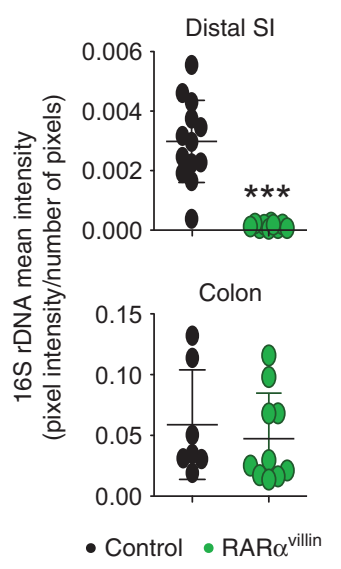

d
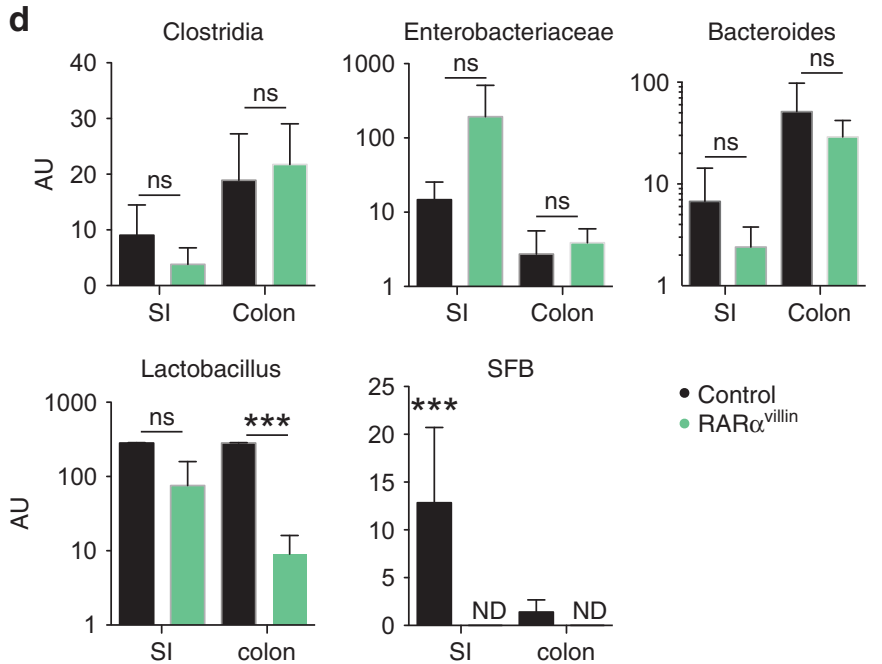

- Control

- RAR $\alpha^{\text {villin }}$

Figure 4 Dysbiosis in RAR $\alpha^{\text {villin }}$ mice. (a) Quantitative PCR (qPCR) analysis from fluorescence-activated cell (FACS)-sorted epithelial cells $\left(\mathrm{CD}_{4} 5^{\mathrm{neg}} \mathrm{EpCAM}^{+}\right)$obtained from the proximal or distal small intestine of either control or RAR $\alpha^{\text {villin }}$ mice. Data show transcript levels as arbitrary units (A. U.) respect to $\mathrm{Hprt}(n=3 \mathrm{mice})$. (b) Fluorescence in situ hybridization of universal $16 \mathrm{~S}$ ribosomal RNA in DAPI (4',6-diamidino-2-phenylindole)-stained ileal tissues from control and RAR $\alpha^{\text {villin }}$ mice. Original magnification, $\times 10$. One representative image of three to six images per mouse $(n=2$ mice). (c) 16S rDNA mean intensities (sum of pixel intensities per number of pixels) are reported. Scale bar, $10 \mu \mathrm{m}$. (d) qPCR analysis shows A.U. of Lactobacillus, Enterobacteriaceae (entero), Bacteroides, Clostridia, and segmented filamentous bacteria (SFB) relative to universal 16S levels. Bacterial DNA was isolated from luminal stool obtained from the small intestine (SI) or colon ( $n=3$; 2 experiments). ${ }^{*} P<0.05$ and ${ }^{* * *} P<0.005$; ns, non-significant; ND, nondetected; Student's $t$-test. Results are shown as meanbs.e.m. in all panels. Scale bar, $250 \mu \mathrm{m}$ (b).

propria in both $\mathrm{RAR} \alpha^{\text {villin }}$ and control mice (Figure 6a), suggesting that decreased numbers of $\mathrm{ALDE}^{+}$dendritic cells in RAR $\alpha^{\text {villin }}$ mice do not result in reduced T-cell intestinal recruitment. Staining with CD90 allowed us to analyze the presence of ILCs $\left(\mathrm{CD} 90^{+} \mathrm{CD} 3^{-}\right)$, presumably lymphoid tissue inducer cells, as they clustered in cryptopatches (Supplementary Figure S3a), defined by the presence of $\mathrm{CD}_{11 \mathrm{c}^{+}}$but not for $\mathrm{CD}^{+}$cells (Supplementary Figure 


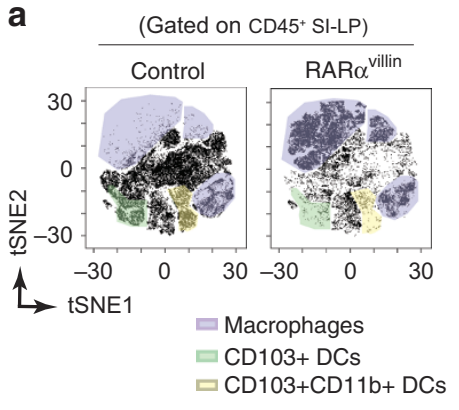

b
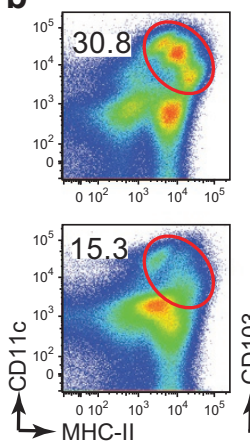

$\rightarrow$
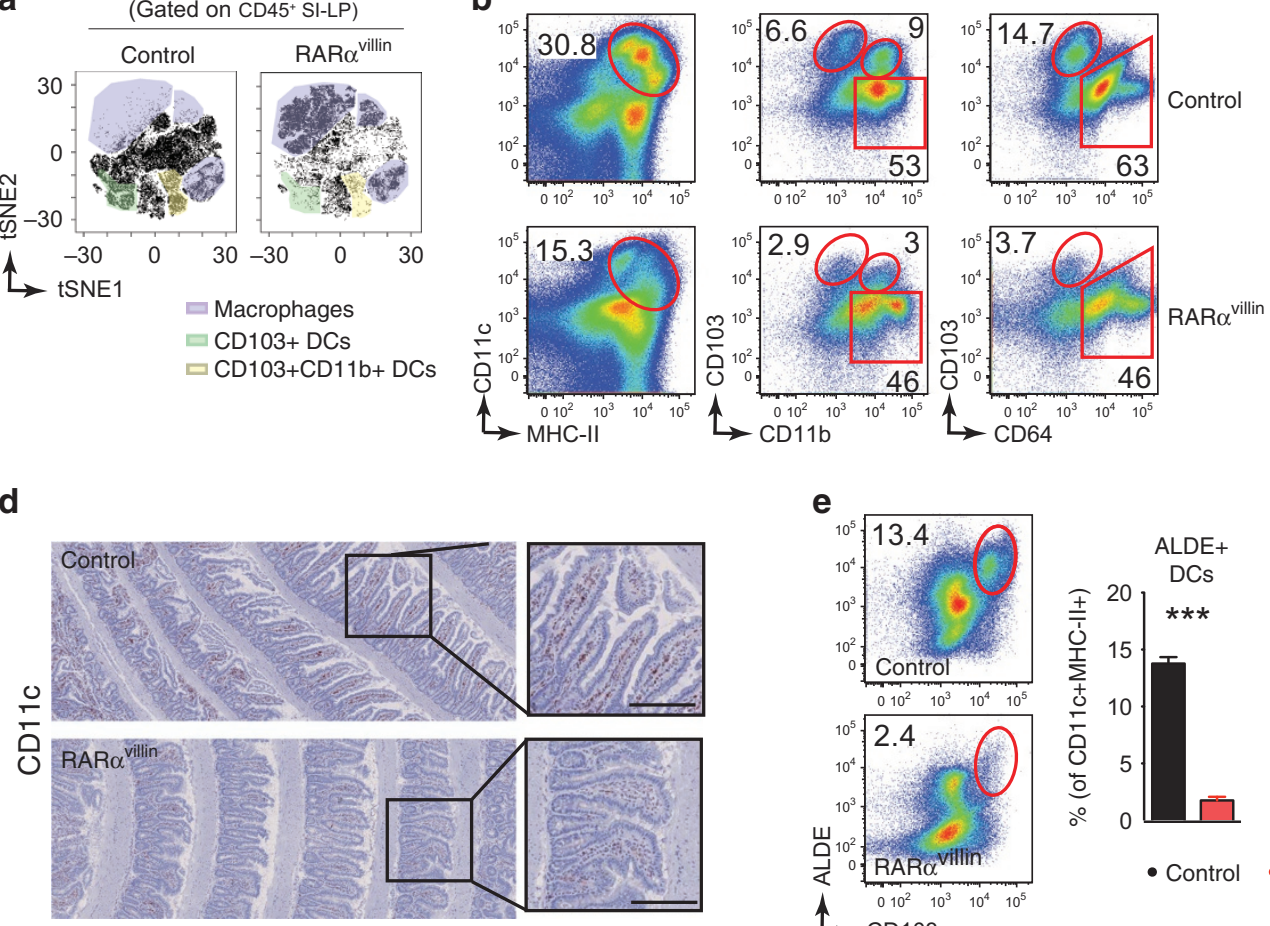

e

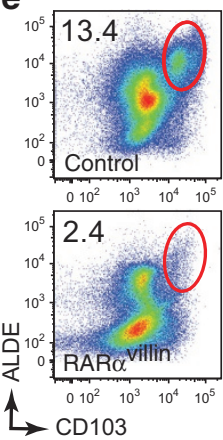

C

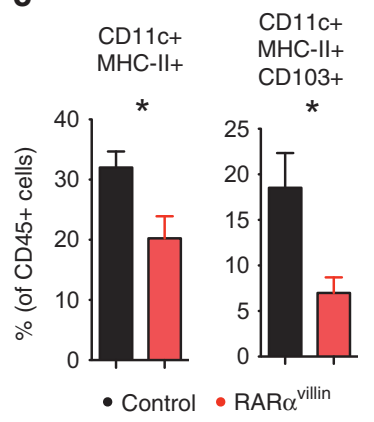

Figure 5 Dendritic cell numbers are decreased in RAR $\alpha^{\text {villin }}$ mice. Cell suspensions from small intestinal lamina propria were analyzed by fluorescenceactivated cell sorting (FACS). (a) Analysis of single live $\mathrm{CD} 45^{+}$events from the flow cytometry data of small intestine (SI) lamina propria isolated form control or RAR $\alpha^{\text {villin }}$ mice using the t-distributed stochastic linear embedding (tSNE) algorithm (one representative analysis of two) (b) Representative dot plots showing total dendritic cells (left column) and subsets defined by CD103 and CD11b expression (middle column), as well as macrophages defined by CD64 (right column). (c) Quantification of the frequencies of DCs and the CD103 ${ }^{+}$subset. ( $n=4 ; 2$ experiments) (d) Expression of CD11c in the SI was determined by immunohistochemistry. Representative images of six images per mouse ( $n=3$ mice). (e) Representative dot plot and quantification of retinoic acid (RA)-producing dendritic cells in the small intestine lamina propria determined by ALDEFLUOR (ALDE) ( $n=4 ; 2$ experiments). ${ }^{\star} P<0.05$, ${ }^{\star \star} P<0.01$, and ${ }^{\star \star \star} P<0.005$, Student's $t$-test. Results are shown as meanps.e.m. in all panels. Scale bar, $100 \mu \mathrm{m}(\mathbf{d})$.

S2b). No differences were evident in the number of cryptopatches between RAR $\alpha^{\text {villin }}$ and control mice (Supplementary Figure S3c); however, colonic cryptopatches appeared to be larger in $\mathrm{RAR} \alpha^{\text {villin }}$ compared with control mice (Supplementary Figure S2b). Despite an apparent enlargement of cryptopatches, the frequencies of $\mathrm{CD} 90^{+}$cells within the colon lamina propria were significantly reduced in $\mathrm{RAR}^{\text {villin }}$ compared with control mice (Figure $6 \mathbf{b}$ ). These $\mathrm{CD} 0^{+}$cells were mainly composed of $\mathrm{T}$ cells $\left(\mathrm{CD}^{+}\right)$rather than ILCs $\left(\mathrm{CD}^{\mathrm{neg}}\right)$ as seen by decreased frequencies of $\mathrm{CD} 3^{\text {neg }}$ cells within the $\mathrm{CD} 90^{+}$compartment in $\mathrm{RAR} \alpha^{\text {villin }}$ compared with control mice (Figure 6c). Colonic cryptopatches can develop into mature isolated lymphoid follicles, which are composed mainly of B cells. ${ }^{42}$ Staining with B220 to detect mature lymphoid follicles revealed a lack of these structures in RAR $\alpha^{\text {villin }}$ mice (Figure 6d). In addition, the colon lamina propria from RAR $\alpha^{\text {villin }}$ mice showed decreased frequencies of ${\mathrm{B} 220^{+}}^{\mathrm{B}}$ cells compared with control (Figure 6e), indicating that B-cell numbers and isolated lymphoid follicle structures were decreased in mice lacking RAR $\alpha$ signaling specifically in IECs, likely to be due to defects in the transition from cryptopatches to isolated lymphoid follicles. Altogether, these data demonstrate that RAR $\alpha$ signaling in IECs is critical to the maintenance of intestinal immune homeostasis.

\section{RAR $\alpha$ deficiency in IECs confers increased susceptibility to C. rodentium infection}

We further explored the ability of RAR $\alpha$ signaling in IECs to regulate intestinal immunity during infection. C. rodentium is a well-studied Gram-negative mouse intestinal pathogen related to adherent invasive Escherichia coli, a cause of serious human infection that is associated with intestinal lesions in Crohn's disease. ${ }^{43}$ Murine infection with C. rodentium results in a distal colitis that is generally cleared $2-3$ weeks post infection by immunocompetent mice. Clearance requires both innate and adaptive immunity with a particularly important role for dendritic cells and ILCs. ${ }^{44}$ Given the profound impact of RAR $\alpha$ signaling deficiency in IECs upon the composition of epithelial, myeloid, and isolated lymphoid follicle compartments, we hypothesized that RAR $\alpha^{\text {villin }}$ mice would differ from control littermates in their response to $C$. rodentium infection. Indeed, $\mathrm{RAR} \alpha^{\text {villin }}$ mice were slower to clear the infection relative to their control littermates as determined by whole-body bioluminescence, stool colony-forming unit, and bacterial translocation to spleen and mesenteric lymph nodes (Figure $7 \mathbf{a}-\mathbf{c}$ ) and lost more weight during C. rodentium 

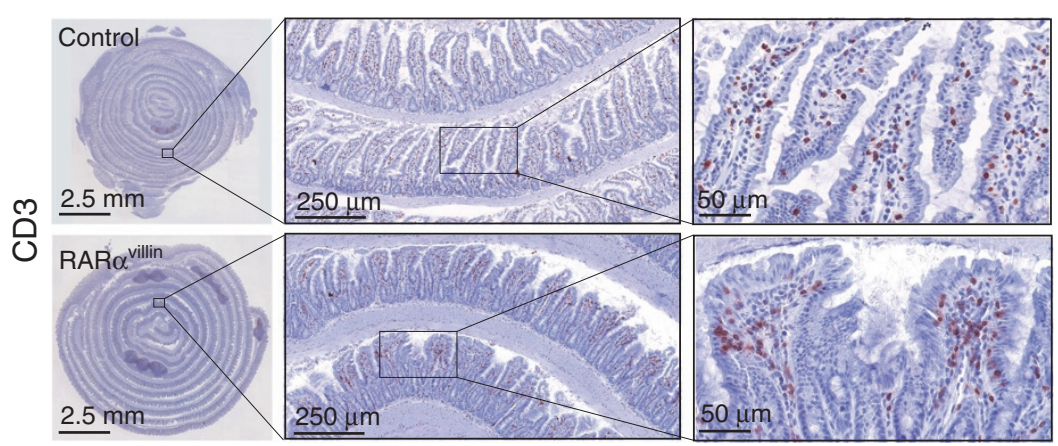

b

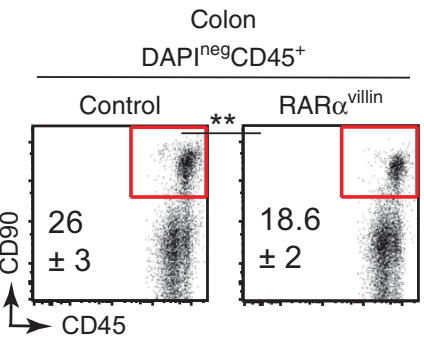

C

Colon

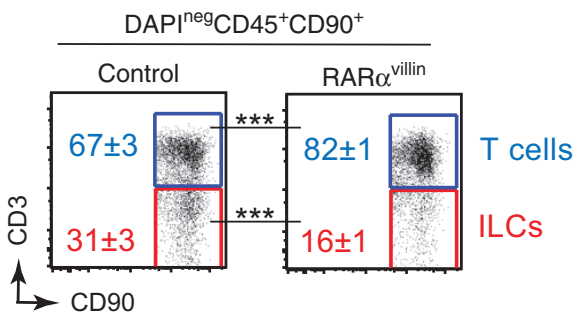

d

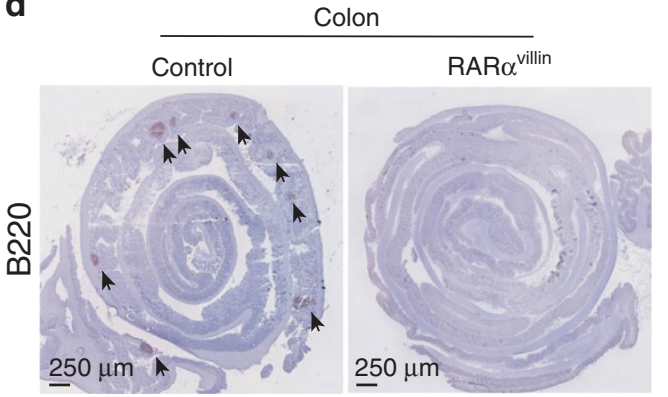

e

Colon

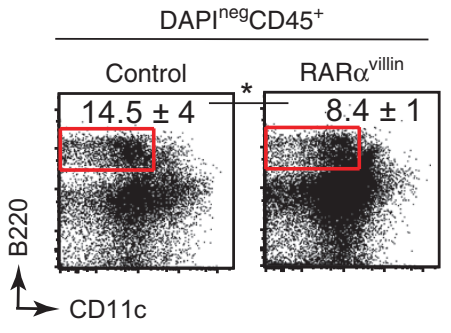

Figure 6 Retinoic acid receptor- $\alpha(\operatorname{RAR} \alpha)$ deficiency results in altered intestinal immune development. (a) Expression of CD3 in the small intestine was determined by immunohistochemistry. Representative image of six images per mouse $\left(n=3\right.$ mice). (b, c) Representative dot plots showing total CD $90{ }^{+}$ cells (b) and T cells and innate lymphoid cells (ILCs) within the CD90 ${ }^{+}$compartment (c) ( $n=3-4$; 2 experiments). (d) Colon Swiss rolls showing immunohistochemistry for B220 in control and RAR $\alpha^{\text {villin }}$ mice. Data are representative of three mice per genotype. (e) Colon cell suspension staining for B220 and CD11c reveals decreased B cells in RAR $\alpha^{\text {villin }}$ mice ( $n=3 ; 2$ experiments). ${ }^{*} P<0.05$, ${ }^{\star \star} P<0.01$, and ${ }^{\star * \star} P<0.005 ;$ Student's $t$-test. Results are shown as meanps.d. in all panels. Scale bars as indicated.

infection (Figure 7d). Collectively, our results place RAR $\alpha$ signaling within the epithelial cell compartment as critical in controlling intestinal immunity (Figure 8).

\section{DISCUSSION}

RA is known to be critical for proper immune function in the intestine. However, much of the research in this context has centered on immune cells, with the question of whether RA signaling in IECs contributes to immune homeostasis in the gut remaining largely unexplored. In the present study, we describe RAR $\alpha$-dependent epithelial cellular linage commitment and resultant changes in epithelial function, linking these alterations to several important changes in the immune compartment, highlighting a previously unrecognized role for intestinal epithelial retinoid signaling in the regulation of intestinal immune homeostasis.
Examination of intestinal hematoxylin and eosin-stained sections from these mice suggested differences in the numbers of secretory epithelial cells. Indeed, defective $\mathrm{RAR} \alpha^{\text {villin }}$ signaling resulted in a marked increase in the numbers of goblet cells and changes in the distribution of Paneth cells along the crypt-villus axis as well as decreased numbers of enteroendocrine cells. These findings suggest that RAR $\alpha$ has a critical role in cell fate determination in the intestine, in keeping with its well-known role as a morphogen. The intestinal epithelium is continuously turning over. The stem cells in the base of the crypt divide to give rise to cellular progenitors with cell fate-determination in the intestine under the control of various signaling pathways including Wnt, bone morphogenic protein (BMP), epidermal growth factor (EGF), and Notch signaling. The Notch pathway has a critical role in IEC fate by regulating the choice of absorptive versus secretory lineages. Hyperactivated Notch signaling expands the 


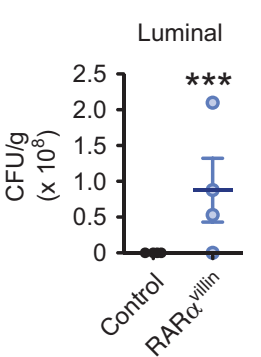

Week 2 upon infection

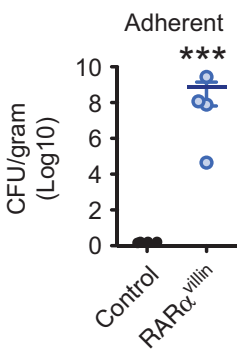

b

Week 2 upon infection

Colon (adherent) Spleen
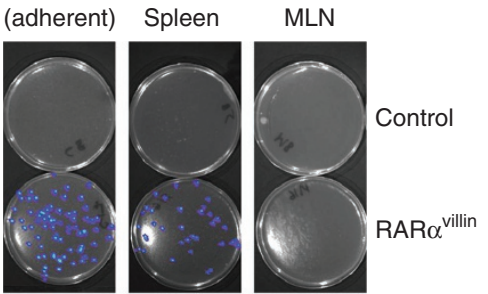

C

Week 2 upon infection

Control

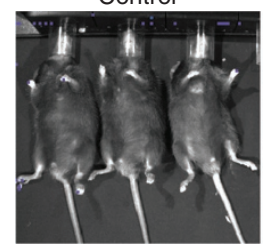

RAR $\alpha^{\text {villin }}$

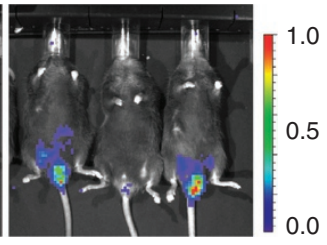

d

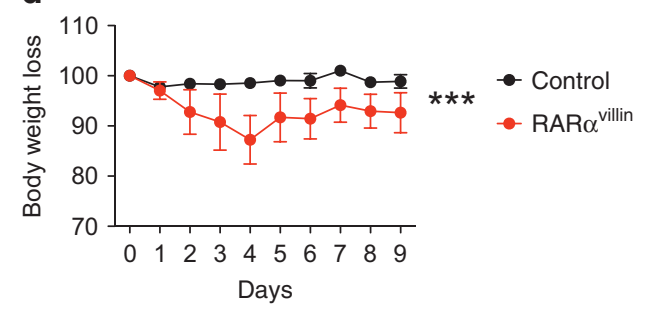

Figure 7 Retinoic acid receptor- $\alpha(\operatorname{RAR} \alpha)$ deficiency in the epithelial compartment results in defective clearance of $C$. rodentium. (a) Colony-forming unit (CFU) from control and RAR $\alpha^{\text {villin }}$ mice infected with $C$. rodentium. ( $n=4 ; 2$ experiments). (b) Bioluminescence of cultured stool samples (colon), spleen, and MLN cell suspensions. (c) Bioluminescence of whole animal. (d) Body weight loss curves from control and RAR $\alpha^{\text {villin }}$ mice infected with C. rodentium $\left(2 \times 10^{9} \mathrm{CFU}\right)$. $\left(n=5 ; 2\right.$ experiments, ${ }^{* * *} P<0.005$; two-way repeated measures analysis of variance with Bonferroni post test (a). Student's $t$-test $(\mathbf{c})$.

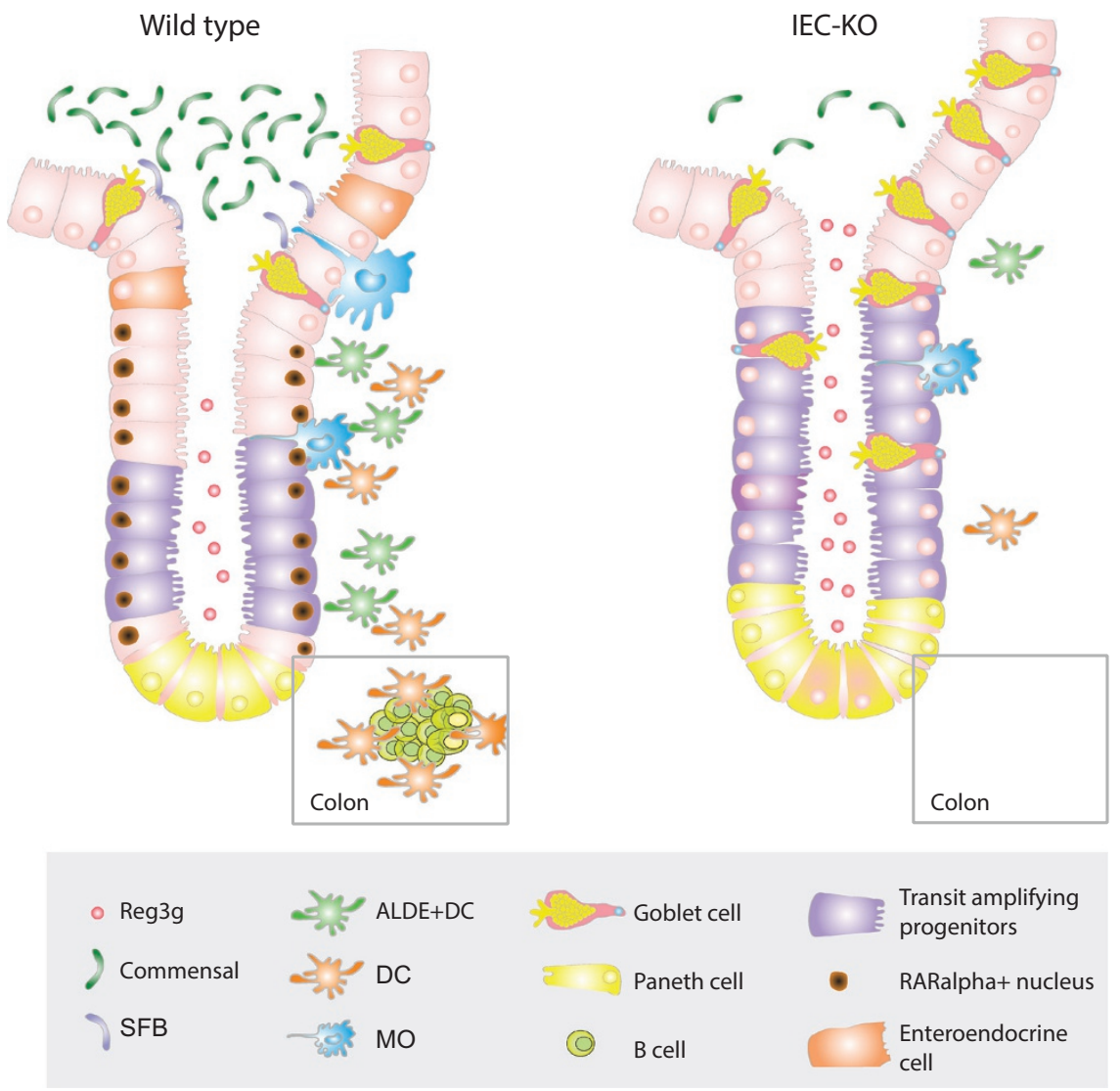

Figure 8 Retinoic acid receptor- $\alpha($ RAR $\alpha$ ) signaling on intestinal epithelial cells (IECs) regulates intestinal secretory cell differentiation and immunological fitness. Scheme showing the proposed model in which RAR $\alpha$ expression in proliferating cells (transit amplifying progenitors) restrict secretory cell differentiation and Reg3g expression, which is associated to proper microbiota composition and immune cell development. 
proliferative zone and suppresses secretory lineage commitment. ${ }^{45}$ This is due to Hes1 (Notch-dependent transcription factor) inhibition of Math1 (also known as Atoh1), a determinant of secretory lineage differentiation. ${ }^{46}$ Importantly, inducible deletion of Math 1 in the mouse intestine results in the almost complete absence of all secretory epithelial cell types including goblet cells, Paneth cells, and enteroendocrine cells. ${ }^{47}$ Our RAR $\alpha^{\text {villin }}$ mice showed no differences in Hes1 activity compared with controls (data not shown).

Given the phenotype observed in our RAR $\alpha^{\text {villin }}$ mice, with increased goblet and Paneth cells but decreased enteroendocrine suggests that RAR $\alpha$ could be participating in the determination of cellular fate within the secretory branch, but after secretory progenitor commitment. Further differentiation of the secretory lineage into goblet, enteroendocrine, and Paneth cells requires other factors like Klf4, Neurogenin3 and beta-catenin, respectively. ${ }^{30} \mathrm{Klf} 4$ is a transcription factor that has a determinant role inhibiting intestinal cell proliferation and regulates goblet cell maturation. ${ }^{30}$ Interestingly, Klf4 is under direct regulation of $\mathrm{RAR} \alpha^{48}$ and Klf4 depletion specifically in IECs leads to increased transit amplifying compartment, increased number, and altered positioning of Paneth cells along the crypt-villus axis ${ }^{49}$ similar to RAR $\alpha^{\text {villin }}$ mice.

We observed an upregulation of Klf4 in RAR $\alpha^{\text {villin }}$ intestinal crypts, particularly in distal small intestine and colon, and retinoid treatment of zebrafish reduced goblet cell differentiation. Therefore, RAR $\alpha$ could be placed downstream of the master regulator of secretory cells, Math1, but upstream Klf4 in the hierarchical regulation of IEC differentiation.

Paneth cells and goblet cells are secretory epithelial cells that have a critical role in the maintenance of microbial epithelial homeostasis through the production and release of AMPs and mucins. These products limit the direct interaction between the intestinal epithelium and the stem cell niche (crypts of Lieberkuhn) and the microbiota. It is possible that RA signaling impacts AMP secretion/activity, such as has been demonstrated in skin, and resulting in changes in stool microbial composition and bacterial proximity to the epithelial surface. ${ }^{50}$ Whether RA induces AMP through direct binding of RAR to their cisregulatory elements needs further investigation. Previous reports have demonstrated a critical role for bacterial products (i.e., pathogen-associated molecular patterns) and their receptors in the development of the intestinal immune system. ${ }^{51}$ In fact, diminished bacterial sensing by the intestinal immune system leads to an underdeveloped immune system manifested by decreases in mononuclear phagocytic cells and reduction in isolated lymphoid follicle numbers and size. ${ }^{52}$ This prompted us to speculate that changes in the microbiota composition might contribute to a defect in intestinal immune development in RAR $\alpha^{\text {villin }}$ mice. By contrast, RA controls the function of lymphoid tissue inducer beginning in the fetal stages in a microbiota-independent manner. Importantly, low maternal levels of RA results in underdeveloped secondary lymphoid structures in the offspring, including isolated lymphoid follicles and Peyer's patches, defects that are not reversed by the addition of dietary vitamin A after birth. ${ }^{14}$ Our data showing the absence of isolated lymphoid follicles in RAR $\alpha^{\text {villin }}$ mice compared with control mice suggest that RAR $\alpha$ signaling in epithelial cells is not completely required to induce the formation of maternal-driven secondary lymphoid organs. Indeed, the accumulation of $\mathrm{CD} 90^{+} \mathrm{CD} 3^{\text {neg }}$ lymphoid tissue inducer-like cells in colonic cryptopatches rather suggests a defect in the transition from cryptopatches (containing lymphoid tissue inducer) toward fully mature isolated lymphoid follicles (containing B cells) in RAR ${ }^{\text {villin }}$ mice. The precise mechanism by which RAR $\alpha$ signaling in IECs controls the maturation of isolated lymphoid follicles will be the subject of future studies.

Interestingly, despite profound differences in epithelial cellular composition between RAR $\alpha^{\text {villin }}$ and control mice, we did not observe any major differences in intestinal paracellular permeability using FITC-dextran (data not shown). This finding is in agreement with previous in vitro observation that various RAR ligands do not affect permeability of Caco-2 intestinal epithelial monolayers. ${ }^{53}$ In contrast, Baltes et al. ${ }^{54}$ have shown an increase in intestinal permeability in response to RA using these same cells. It would therefore be expected that defective RA signaling would result in decreased permeability, which would not be detected by our assay given the poor permeability of FITC-dextran at baseline. ${ }^{54}$

In considering how RAR $\alpha$ may regulate cell fate, it is important to survey the roles of RAR $\alpha$ as both a transcriptional activator and repressor. In the absence of ligand, RAR $\alpha$ is known to occupy RA responsive elements while coupled to transcriptional repressors such as NCOR. On the other hand, when ligand bound, RAR activates transcription through the release of repressors and recruitment of coactivators such as histone deacetylases. It is therefore possible that the changes observed within the epithelial compartment are in part due to de-repression of otherwise silenced promoters in RAR $\alpha^{\text {villin }}$ mice rather than absence of RA-dependent signaling. Similarly, one must be cautious when comparing our in vivo results with studies examining RA-dependent signaling via the use of RAR $\alpha$ agonists. Nevertheless, RA supplementation was recently shown to suppress intestinal mucus production in a zebrafish model of enterocolitis, in keeping with our observed increase in goblet cell numbers in RAR $\alpha^{\text {villin }}$ mice. ${ }^{55}$

In conclusion, we have shown that RAR $\alpha$ signaling in the intestinal epithelia influences the cellular linage composition in the intestinal barrier, which is associated with dramatic alterations in intestinal immune homeostasis and protective responses against bacterial infection (Figure 8). The identification of this dominant role of $\operatorname{RAR} \alpha$ signaling within IECs in modulating intestinal immune homeostasis raises new and interesting questions regarding the cell-intrinsic roles of RA in settings of nutritional deprivation and RA supplementation.

\section{EXPERIMENTAL PROCEDURES}

Animal husbandry. RAR $\alpha^{\mathrm{f} / \mathrm{f}}$ have been previously described. ${ }^{56}$ $\mathrm{RAR} \alpha^{\mathrm{f} / \mathrm{f}}$ mice were crossed with villin-cre mice to generate 
$\mathrm{RAR} \alpha^{\text {villin }}$ mice. Mice were in a C57/BL/6 background. All mice were used between 8 and 12 weeks of age. Where indicated, mice were intraperitoneally administered $2.4 \mathrm{mg}$ BrdU $2 \mathrm{~h}$ before killing. Mice were maintained under specific pathogen-free conditions and handled according to protocols approved by the Institutional Animal Care and Use Committee at Massachusetts General Hospital. Zebrafish (Danio rerio) embryos were obtained from natural spawnings and raised at $28.5^{\circ} \mathrm{C}$ in $\mathrm{E} 3$ water supplemented with methylene blue and HEPES $(10 \mathrm{~mm})$. Embryos were exposed to all-trans RA from 72 to $108 \mathrm{~h}$ post fertilization in groups of 20 embryos in a volume of $5 \mathrm{ml}$. The exposure medium was renewed at $96 \mathrm{~h}$ post fertilization. All analyses were performed at $108 \mathrm{~h}$ post fertilization. RA (Catalog Number R2625, Sigma-Aldrich, St Louis, MO) was dissolved in dimethyl sulfoxide and diluted to working concentrations with E3 water.

Fluorescence in situ hybridization. Small intestinal tissues (distal ileum) were prepared for analysis by fixation in Carnoy's fixative followed by embedding in paraffin and sectioning to $5 \mu \mathrm{m}$. Processing and hybridizations to a universal bacterial probe $(100 \mu \mathrm{M})$ directed against the 16S rRNA gene ((Alexa488)-GCTGCCTCCCGTAGGAGT-(Alexa488)) were carried out using DAPI (4',6-diamidino-2phenylindole) as a counterstain. ${ }^{34}$ Tissues were visualized using a CHGR Leika SP5 microscope (Buffalo Grove, IL) and captured using LASAF software (Buffalo Grove, IL). Pictures were taken under $\times 10$ magnification and analyzed in an automated manner using the opensource CellProfiler software (Broad Institute, Cambridge, MA; www. cellprofiler.org). Mean intensities (the sum of pixel intensities/number of pixels) are reported.

IEC and lamina propria isolation. Colon and small intestine lamina propria cells were isolated as previously described ${ }^{18}$ with slight modification. Briefly, intestines were harvested and placed in ice-cold Hank's balanced salt solution. After removal of residual mesenteric fat tissue, Peyer's patches were excised (in the case of small intestine dissection) and the intestines were opened longitudinally. Tissues were then washed in ice-cold Hank's balanced salt solution and cut into 1$\mathrm{cm}$ pieces. After three more washes in Hank's balanced salt solution, tissues were incubated twice in $20 \mathrm{ml}$ of serum-free media with $5 \mathrm{~mm}$ EDTA and $0.145 \mathrm{mg} \mathrm{ml}^{-1}$ dithiothreitol at $37^{\circ} \mathrm{C}$ at 250 r.p.m. for $30 \mathrm{~min}$. The supernatant was harvested by filtration through a $100 \mu \mathrm{m}$ cell strainer and centrifugation at $500 \mathrm{~g}$; the pellet, consisting of the IEC fraction, was resuspended in FACS buffer. Tissue pieces were washed three times with $10 \mathrm{ml}$ serum-free media with $2 \mathrm{~mm}$ EDTA. Small intestine pieces were next digested in serum-free media containing Liberase TL $\left(0.1 \mathrm{mg} \mathrm{ml}^{-1}\right.$, Roche, Indianapolis, IN $)$ at $37^{\circ} \mathrm{C}$ at 250 r.p. $\mathrm{m}$. for $45 \mathrm{~min}$. Cells were washed and passed through a $70 \mu \mathrm{m}$ cell strainer. Cells were resuspended in $4.5 \mathrm{ml}$ of $44 \%$ Percoll. A quantity of $2.3 \mathrm{ml}$ of $67 \%$ Percoll were then underlaid. Percoll gradient separation was performed by centrifugation for $20 \mathrm{~min}$ at $600 \mathrm{~g}$ at room temperature. Lymphoid fractions were collected at the interphase of the Percoll gradient, washed once, and resuspended in fluorescence activated cell sorting (FACS) buffer (1\% fetal bovine serum (FBS) phosphate buffered saline (PBS)) or culture medium.

Flow cytometry. Single cell suspensions were incubated for $10 \mathrm{~min}$ at room temperature with Fc blocking (CD16/32) antibody (eBioscience, San Diego, CA) beforestaining with fluorochrome-conjugated antibodies against mixtures of the following antigens: CD90.2, CD45, CD3e, CD11c, CD11b, GR1, MHCII, CD103, CD4, CD8 $\alpha$, CD8 $\beta$, TCR- $\gamma \delta$, and B220 (all from Biolegend, Dedham, MA). DAPI or Live/ Dead Fixable Blue Dead Cell Stain Kit (Invitrogen, Grand Island, NY) were used to exclude dead cells. Multiparameter analysis was performed on a LSR II (BD, San Diego, CA) and bi-dimensional dot plots were generated using FlowJo software (Tree Star, Ashland, OR), whereas $\mathrm{t}$-distributed stochastic neighbor embedding high dimensional plots using Cytobank. ${ }^{37}$
Quantitative real-time PCR. Distal small intestine (ileum) and proximal colon (colon) tissues were collected and stored in RNAlater (Ambion, Austin, TX). RNA was extracted from homogenized tissues using the RNeasy Kit (Qiagen, Frederick, MD). Total RNA was isolated from pools of 20 zebrafish embryos using TRIzol LS reagent (Invitrogen), according to the manufacturer's protocol. RNA samples were reverse-transcribed using the iScript cDNA Synthesis kit (Bio-Rad, Portland, ME). Using the iQ SYBR Green Supermix (Bio-Rad) for quantitative PCR, mRNA levels were determined using the iCycler with iQ5 Multicolor Real-Time PCR Detection System (Bio-Rad). Reaction conditions consisted of 40 cycles of PCR with $58^{\circ} \mathrm{C}$ or $59^{\circ} \mathrm{C}$ annealing temperature. Mouse primers sequences have been previously described and are as follows: ${ }^{57}$ Clostridia F-5'-ACT CCT ACG GGA GGC AGC-3' ${ }^{\prime}$, Clostridia R-5'-GCT TCT TAG TCA GGT ACC GTC AT-3'; segmented filamentous bacteria F-5'-GAC GCT GAG GCA TGA GAG CAT-3' ${ }^{\prime}$, segmented filamentous bacteria R-5'-GAC GGC ACG GAT TGT TAT TCA-3'; Lactobacillus F-5'-AGC AGT AGG GAA TCT TCC A-3', Lactobacillus R-5' -CGC CAC TGG TGT TCY TCC ATA TA-3'; Bacteroidetes F-5'-GGT TCT GAG AGG AGG TCC C-3', Bacteroidetes R-5'-GCT GCC TCC CGT AGG AGT-3'; Enterobacteriaceae F-5'-GTG CCA GCM GCC GCG GTA A-3', Enterobacteriaceae R-5'-GCC TCA AGG GCA CAA CCT CCA AG3'; Muc2 F-5'-AGG GCT CGG AAC TCC AGA AA-3', Muc2 R-5'CCA GGG AAT CGG TAG ACA TCG- $3^{\prime}$; Chga F-5' ${ }^{\prime}$-CCC ACT GCA GCA TCC AGT T-3', Chga R-5'-AGT CCG ACT GAC CAT CAT CTT TC-3'; Lys1 F-5'-AGA ATG CCT GTG GGA TCA AT-3', Lys1 R-5'-CTG GGA CAG ATC TCG GTT TT-3'; Lgr5 F-5'-CCT ACT CGA AGA CTT ACC CAG T-3', Lgr5 R-5'-GCA TTG GGG TGA ATG ATA GCA-3'; Dhrs 3 F-5'-GCG CTG GTA GTG TTC CCT C-3', Dhrs3 R-5' -GGT GTT GAC ATG CTG GGA CTT-3' ; and Gapdh F-5' CAT GGC CTT CCG TGT TCC TA-3', Gapdh R-5'-GCG GCA CGT CAG ATC CA- $3^{\prime}$. Zebrafish primers sequences are as follows: klf4 F-5'-CGG TTC AAG ATG GAA GGA GGA-3' ${ }^{\prime}$, klf4 R-5' -CTG TTG AAG CAA GCT GTT CG-3'; efla F-5'-ACC TAC CCT CCT CTT GGT CG-3', efla R-5'-GGA ACG GTG TGA TTG AGG GAA- $3^{\prime}$; and cyp26a1 F-5'-GAT GCT CTG GAG CAC TAC ATT C-3', сур26a1 R-5'-GTT CTT GCT CGT CCG TCT TTA T-3'.

Immunohistochemistry. Small intestines and colons were flushed with PBS prior to fixation in $10 \%$ neutral buffered formalin and paraffin embedding. Four-micrometer sections were de-waxed and rehydrated before heat-mediated antigen retrieval in citrate buffer $(\mathrm{pH}$ 6). Anti-chromogranin A (Abcam, Cambridge, MA, ab15160, 1:3,000), anti-RAR $\alpha$ (Santa Cruz Biotechnology, Dallas, TX, 1:500), anti-Crerecombinase (Cell Signaling Technologies, Danvers, MA, 1:200), anticleaved caspase 3 (Cell Signaling Technologies, 1:400), anti-olfactomedin-4 (Cell Signaling Technologies, Danvers, MA, 1:400), anti KLF4 (R\&D Systems, Minneapolis, MN, 1:200), and anti-Ki67 (Biolegend, 16A8, 1:50) antibodies were used for immunohistochemistry. Borg decloaker solution was used for antigen retrieval prior anti-Lysozyme antibody incubation (Thermo Ab-1 RB-372-A1, 1:2,000) for Paneth cells detection. Samples were hematoxylin counterstained before mounting. For goblet cell staining, slides were incubated in $1 \%$ Alcian Blue $/ 3 \%$ acetic acid solution for $5 \mathrm{~min}$ and counterstained with nuclear fast red. Pictures taken under $\times 10$ magnification were blindly quantified using ImageJ (NIH, Bethesda, MD) software.

For whole organ analysis, small intestines and colons were prepared as Swiss rolls before fixation. Tissues were placed in cassettes and submerged in OCT compound (Tissue Tek, Torrance, CA), and submerged in isopentane cooled with liquid nitrogen and stored at $-80^{\circ} \mathrm{C}$. Five-micrometer sections were then stained using the following antibodies: CD90.2 (BD Bioscience, San Diego, CA, clone 53-2.1, 1:50), CD3 (BD Bioscience, clone 17A2, 1:50), B220 (BD Bioscience, clone RA3-6B2, 1:50), and CD11c (BD Bioscience, clone HL3, 1:50). 
Zebrafish Alcian Blue staining. Whole-mount alcian blue staining of zebrafish embryos was performed as previously described. ${ }^{58}$ Larvae were mounted in glycerol and imaged using a Leica M165 FC stereomicroscope equipped with a Leica DFC450 C digital camera (Leica, Wetzlar, Germany). Quantification of positive cells from the middle segment of the intestinal tract to the anus per intestine was performed manually.

Immunofluorescence. Paraffin-embedded sections were dewaxed and rehydrated following regular immunohistochemistry procedures. Blocking was done in $10 \%$ goat serum IF buffer-0.1\% BSA, $0.2 \%$ Triton, $0.5 \%$ Tween 20 in PBS. Primary antibodies were incubated at $4{ }^{\circ} \mathrm{C}$ overnight (Anti-BrdU, BD Pharmingen, San Jose, CA, 1:200; antiLysozyme, Thermo, Waltham, MA, Ab-1 RB-372-A1 1:2,000; and anti-mucin 2, Santa Cruz Biotechnology sc-15334 1:200). Fluorescence-labeled secondary antibodies were used at 1:2,000 dilution in IF buffer (anti-mouse AF488 and anti-rabbit AF555). DAPI was used for DNA counterstain before imaging using a DeltaVision (GE Healthcare, Garretsville, $\mathrm{OH}$ ) confocal microscope.

C. rodentium infection. Bioluminescent $C$. rodentium strain ICC180 (derived from DBS100) was used for all inoculations (provided by Dr. Gad Frankel, Imperial College London). ${ }^{59}$ C. rodentium was grown overnight in Luria-Bertani broth with shaking at $37^{\circ} \mathrm{C}$ in the presence of $50 \mu \mathrm{g} \mathrm{ml}^{-1}$ kanamycin. The following morning, cultures were diluted to optical density $=1$ followed by an additional $5 \mathrm{~h}$ of growth. Bacterial density was confirmed by dilution plating. Eight- to 12 -weekold sex-matched mice were inoculated by oral gavage with $2 \times 10^{9}$ colony-forming unit resuspended in $200 \mu \mathrm{l}$ PBS. For quantification of bacterial shedding and spleen translocation, stool pellets and spleens from individual mice were weighed, homogenized in PBS, and plated in serial dilutions on LB agar containing $50 \mu \mathrm{g} \mathrm{ml}^{-1}$ kanamycin. Mice were killed on day14 post infection.

Bioluminescence imaging. Mice were anesthetized with isoflurane and placed in a supine position in a custom-built chamber for imaging with an IVIS-100 system and Living Image Software (Xenogen, Alameda, CA). Whole-body images were taken over 1 to $3 \min 4,7,10$, and 14 days post infection. Luminescence emitted from the same gate in individual mice was quantified as counts per second and pseudocolor images were generated representing light intensity.

SUPPLEMENTARY MATERIAL is linked to the online version of the paper at http://www.nature.com/mi

\section{ACKNOWLEDGMENTS}

We thank Natalia Nedelsky for editorial assistance and members of the Villablanca lab for helpful comments. This work was supported in part by an Alberta Innovates-Health Solutions Fellowship, 201100215 to H.B.J., the Samana Cay MGH Research Scholar Fund and R01-AI084880 to M.J.P., the Helmsley Trust and NIH grants DK097485, DK062432, and DK086502 to R.J.X., and funding from Swedish Research Council VR grant K201568X-22765-01-6 and Wallenberg Academy Fellow (WAF) program to E.J.V.

\section{AUTHOR CONTRIBUTIONS}

H.B.J., L.S.L., O.E.D., S.D., J.D.C., M.P.K., and E.J.V. designed, performed experiments and analyzed the data. M.B.Y., M.J.P., J.R.M., and Y.B. analyzed the data and provided feedback. R.J.X. and E.J.V. conceived the study, designed experiments, analyzed the data, and wrote the manuscript.

\section{DISCLOSURE}

The authors declared no conflict of interest.

(c) 2018 Society for Mucosal Immunology

\section{REFERENCES}

1. Niederreither, K. \& Dolle, P. Retinoic acid in development: towards an integrated view. Nat. Rev. Genet. 9, 541-553 (2008).
2. Czarnewski, P., Das, S., Parigi, S.M. \& Villablanca, E.J. Retinoic acid and its role in modulating intestinal innate immunity. Nutrients 9, 68 (2017).

3. Erkelens, M.N. \& Mebius, R.E. Retinoic acid and immune homeostasis: a balancing act. Trends Immunol. 38, 168-180 (2017).

4. Iwata, M. et al. Retinoic acid imprints gut-homing specificity on T cells. Immunity 21, 527-538 (2004).

5. Mora, J.R. et al. Generation of gut-homing IgA-secreting B cells by intestinal dendritic cells. Science 314, 1157-1160 (2006).

6. Kang, S.G., Lim, H.W., Andrisani, O.M., Broxmeyer, H.E. \& Kim, C.H. Vitamin A metabolites induce gut-homing FoxP3 + regulatory $\mathrm{T}$ cells. J. Immunol. 179, 3724-3733 (2007).

7. Villablanca, E.J. et al. beta7 integrins are required to give rise to intestinal mononuclear phagocytes with tolerogenic potential. Gut 63, 1431-1440 (2014).

8. Kim, M.H., Taparowsky, E.J. \& Kim, C.H. Retinoic acid differentially regulates the migration of innate lymphoid cell subsets to the gut. Immunity 43, 107-119 (2015).

9. Mucida, D. et al. Reciprocal TH17 and regulatory T cell differentiation mediated by retinoic acid. Science 317, 256-260 (2007).

10. Coombes, J.L. et al. A functionally specialized population of mucosal CD103 + DCs induces Foxp3 + regulatory T cells via a TGF-beta and retinoic acid-dependent mechanism. J. Exp. Med. 204, 1757-1764 (2007).

11. Sun, C.M. et al. Small intestine lamina propria dendritic cells promote de novo generation of Foxp3 T reg cells via retinoic acid. J. Exp. Med. 204, 1775-1785 (2007).

12. Tokuyama, Y. \& Tokuyama, H. Retinoids as Ig isotype-switch modulators. Cell. Immunol. 170, 230-234 (1996).

13. Klebanoff, C.A. et al. Retinoic acid controls the homeostasis of pre-cDCderived splenic and intestinal dendritic cells. J. Exp. Med. 210, 1961-1976 (2013).

14. van de Pavert, S.A. et al. Maternal retinoids control type 3 innate lymphoid cells and set the offspring immunity. Nature 508, 123-127 (2014).

15. Goverse, G. et al. Vitamin A controls the presence of RORgamma + innate lymphoid cells and lymphoid tissue in the small intestine. J. Immunol. 196, 5148-5155 (2016).

16. Spencer, S.P. et al. Adaptation of innate lymphoid cells to a micronutrient deficiency promotes type 2 barrier immunity. Science 343, 432-437 (2014).

17. Cassani, B., Villablanca, E.J., De Calisto, J., Wang, S. \& Mora, J.R. Vitamin $A$ and immune regulation: role of retinoic acid in gut-associated dendritic cell education, immune protection and tolerance. Mol. Aspects Med. 33, 63-76 (2012).

18. Villablanca, E.J. et al. MyD88 and retinoic acid signaling pathways interact to modulate gastrointestinal activities of dendritic cells. Gastroenterology 141, 176-185 (2011).

19. Bhattacharya, N. et al. Normalizing microbiota-induced retinoic acid deficiency stimulates protective CD8 $+\mathrm{T}$ cell-mediated immunity in colorectal cancer. Immunity 45, 641-655 (2016).

20. Hall, J.A. et al. Essential role for retinoic acid in the promotion of CD4(+) $T$ cell effector responses via retinoic acid receptor alpha. Immunity 34 , 435-447 (2011).

21. Weston, A.D., Blumberg, B. \& Underhill, T.M. Active repression by unliganded retinoid receptors in development: less is sometimes more. J. Cell Biol. 161, 223-228 (2003).

22. D'Ambrosio, D.N., Clugston, R.D. \& Blaner, W.S. Vitamin A metabolism: an update. Nutrients 3, 63-103 (2011).

23. Barker, N., van de Wetering, M. \& Clevers, H. The intestinal stem cell. Genes Dev. 22, 1856-1864 (2008).

24. Liu, T.C. et al. Paneth cell defects in Crohn's disease patients promote dysbiosis. JCl Insight 1, e86907 (2016).

25. Bevins, C.L. \& Salzman, N.H. Paneth cells, antimicrobial peptides and maintenance of intestinal homeostasis. Nat. Rev. Microbiol. 9, 356-368 (2011).

26. Brown, C.C. et al. Retinoic acid is essential for Th1 cell lineage stability and prevents transition to a Th17 cell program. Immunity 42, 499-511 (2015).

27. Madison, B.B. et al. Cis elements of the villin gene control expression in restricted domains of the vertical (crypt) and horizontal (duodenum, cecum) axes of the intestine. J. Biol. Chem. 277, 33275-33283 (2002). 
28. van der Flier, L.G., Haegebarth, A., Stange, D.E., van de Wetering, M. \& Clevers, H. OLFM4 is a robust marker for stem cells in human intestine and marks a subset of colorectal cancer cells. Gastroenterology 137, 15-17 (2009).

29. Grover, P.K., Hardingham, J.E. \& Cummins, A.G. Stem cell marker olfactomedin 4: critical appraisal of its characteristics and role in tumorigenesis. Cancer Metastasis Rev. 29, 761-775 (2010).

30. Yu, T. et al. Kruppel-like factor 4 regulates intestinal epithelial cell morphology and polarity. PLOS ONE 7, e32492 (2012).

31. Katz, J.P. et al. The zinc-finger transcription factor Klf4 is required for terminal differentiation of goblet cells in the colon. Development $\mathbf{1 2 9}$, 2619-2628 (2002).

32. Brugman, S. The zebrafish as a model to study intestinal inflammation. Dev. Comp. Immunol. 64, 82-92 (2016).

33. Birchenough, G.M., Johansson, M.E., Gustafsson, J.K., Bergstrom, J.H. \& Hansson, G.C. New developments in goblet cell mucus secretion and function. Mucosal Immunol. 8, 712-719 (2015).

34. Vaishnava, S. et al. The antibacterial lectin Reglllgamma promotes the spatial segregation of microbiota and host in the intestine. Science 334, 255-258 (2011).

35. Iliev, I.D. et al. Human intestinal epithelial cells promote the differentiation of tolerogenic dendritic cells. Gut 58, 1481-1489 (2009).

36. Rakoff-Nahoum, S., Paglino, J., Eslami-Varzaneh, F., Edberg, S. \& Medzhitov, R. Recognition of commensal microflora by toll-like receptors is required for intestinal homeostasis. Cell 118, 229-241 (2004).

37. Kotecha, N., Krutzik, P.O. \& Irish, J.M. Web-based analysis and publication of flow cytometry experiments. Curr. Protoc. Cytom. Chapter 10, Unit10 17 (2010).

38. Johansson-Lindbom, B. et al. Functional specialization of gut CD103+ dendritic cells in the regulation of tissue-selective T cell homing. J. Exp. Med. 202, 1063-1073 (2005).

39. Parigi, S.M., Eldh, M., Larssen, P., Gabrielsson, S. \& Villablanca, E.J. Breast milk and solid food shaping intestinal immunity. Front. Immunol. 6, 415 (2015).

40. Yokota, A. et al. GM-CSF and IL-4 synergistically trigger dendritic cells to acquire retinoic acid-producing capacity. Int. Immunol. 21, 361-377 (2009).

41. Luda, K.M. et al. IRF8 transcription-factor-dependent classical dendritic cells are essential for intestinal T cell homeostasis. Immunity 44, 860-874 (2016).

42. Taylor, R.T., Lugering, A., Newell, K.A. \& Williams, I.R. Intestinal cryptopatch formation in mice requires lymphotoxin alpha and the lymphotoxin beta receptor. J. Immunol. 173, 7183-7189 (2004).

43. Darfeuille-Michaud, A. etal. Presence of adherent Escherichia colistrains in ileal mucosa of patients with Crohn's disease. Gastroenterology 115, 1405-1413 (1998).

44. Collins, J.W. et al. Citrobacter rodentium: infection, inflammation and the microbiota. Nat. Rev. Microbiol. 12, 612-623 (2014).
45. Stanger, B.Z., Datar, R., Murtaugh, L.C. \& Melton, D.A. Direct regulation of intestinal fate by Notch. Proc. Natl Acad. Sci. USA 102, 12443-12448 (2005).

46. Yang, Q., Bermingham, N.A., Finegold, M.J. \& Zoghbi, H.Y. Requirement of Math1 for secretory cell lineage commitment in the mouse intestine. Science 294, 2155-2158 (2001).

47. van Es, J.H., de Geest, N., van de Born, M., Clevers, H. \& Hassan, B.A. Intestinal stem cells lacking the Math1 tumour suppressor are refractory to Notch inhibitors. Nat. Commun. 1, 18 (2010).

48. Shi, J.H., Zheng, B., Chen, S., Ma, G.Y. \& Wen, J.K. Retinoic acid receptor alpha mediates all-trans-retinoic acid-induced Klf4 gene expression by regulating Klf4 promoter activity in vascular smooth muscle cells. J. Biol. Chem. 287, 10799-10811 (2012).

49. Ghaleb, A.M., McConnell, B.B., Kaestner, K.H. \& Yang, V.W. Altered intestinal epithelial homeostasis in mice with intestine-specific deletion of the Kruppel-like factor 4 gene. Dev. Biol. 349, 310-320 (2011).

50. Harder, J., Meyer-Hoffert, U., Wehkamp, K., Schwichtenberg, L. \& Schroder, J.M. Differential gene induction of human beta-defensins (hBD-1, -2, -3, and -4) in keratinocytes is inhibited by retinoic acid. J. Invest. Dermatol. 123, 522-529 (2004).

51. Round, J.L. \& Mazmanian, S.K. The gut microbiota shapes intestinal immune responses during health and disease. Nat. Rev. Immunol. 9, 313-323 (2009).

52. Eberl, G. \& Lochner, M. The development of intestinal lymphoid tissues at the interface of self and microbiota. Mucosal Immunol. 2, 478-485 (2009).

53. Wojtal, K.A. et al. The effects of vitamin A on cells of innate immunity in vitro. Toxicol. In Vitro 27, 1525-1532 (2013).

54. Baltes, S., Nau, H. \& Lampen, A. All-trans retinoic acid enhances differentiation and influences permeability of intestinal Caco-2 cells under serum-free conditions. Dev. Growth Differ. 46, 503-514 (2004).

55. Oehlers, S.H., Flores, M.V., Hall, C.J., Crosier, K.E. \& Crosier, P.S. Retinoic acid suppresses intestinal mucus production and exacerbates experimental enterocolitis. Dis Models Mech 5, 457-467 (2012).

56. Chapellier, B. et al. A conditional floxed (loxP-flanked) allele for the retinoic acid receptor alpha (RARalpha) gene. Genesis 32, 87-90 (2002).

57. Bouskra, D. et al. Lymphoid tissue genesis induced by commensals through NOD1 regulates intestinal homeostasis. Nature 456, 507-510 (2008).

58. Oehlers, S.H. et al. Chemically induced intestinal damage models in zebrafish larvae. Zebrafish 10, 184-193 (2013).

59. Wiles, S., Robertson, B.D., Frankel, G. \& Kerton, A. Bioluminescent monitoring of in vivo colonization and clearance dynamics by light-emitting bacteria. Methods Mol. Biol. 574, 137-153 (2009). 